\title{
Multiple intracranial metastases from postoperative giant sarcomatoid malignant pleural mesothelioma: A case report and literature review
}

\author{
DONG TIAN $^{1 *}$, HONGYING WEN $^{1 *}$, HAM EBO BROWN ${ }^{2}$, XIANZHI WANG ${ }^{3}$, LIN ZHANG $^{1}$ and MAOYONG FU ${ }^{1}$ \\ Departments of ${ }^{1}$ Cardiothoracic Surgery, ${ }^{2}$ Urinary Surgery and ${ }^{3}$ Vascular Surgery, \\ Affiliated Hospital of North Sichuan Medical College, Nanchong, Sichuan 637000, P.R. China
}

Received August 30, 2017; Accepted October 31, 2017

DOI: $10.3892 / \mathrm{mco} .2017 .1494$

\begin{abstract}
Sarcomatoid malignant pleural mesothelioma (SMPM) is a rare tumor with poor response to treatment and a dismal prognosis. Distant metastases are not uncommon and usually appear at the late stages of the disease. However, cerebral metastases have rarely been documented. We herein report a case of a giant sarcomatoid carcinoma of the pleura in a 41-year-old male patient with no history of exposure to asbestos, who presented with a chief complaint of left-sided chest pain for 1 month. Extrapleural pneumonectomy and rib excision were performed. At 5 months after the surgery, the patient was diagnosed with multiple intracranial metastatic neoplasms and succumbed to the disease soon thereafter. The aim of the present case report was to emphasize this rare metastatic pattern and aggressive clinical course of SMPM, with a supplementary review of the previously published literature.
\end{abstract}

\section{Introduction}

Malignant pleural mesothelioma (MPM) is relatively rare (1-5). The World Health Organization has classified MPM into three types, namely epithelioid, sarcomatoid and biphasic types. Only $10 \%$ of MPMs are classified as sarcomatoid malignant

Correspondence to: Dr Maoyong Fu, Department of Cardiothoracic Surgery, Affiliated Hospital of North Sichuan Medical College, 63 Wenhua Road, Shunqing, Nanchong, Sichuan 637000, P.R. China E-mail: fumaoyongmd@126.com

\section{${ }^{*}$ Contributed equally}

Abbreviations: MPM, malignant pleural mesothelioma; SMPM, sarcomatoid malignant pleural mesothelioma; CT, computed tomography; ECT, emission computed tomography; EPP, extrapleural pneumonectomy; CNS, central nervous system

Key words: sarcomatoid carcinoma, pleura, malignant tumor, mesothelioma, intracranial metastasis pleural mesothelioma (SMPM), which is associated with a worse prognosis (6).

Distant metastases usually appear during the late stages of the disease. However, reported cases of intracranial metastases are extremely rare, with only few published articles to date on intracranial metastases from MPM (7-11), and only 1 reported case of multiple intracranial metastases from SMPM (8).

We herein report a case of multiple intracranial metastases from a giant SMPM in a 41-year-old male patient with no history of asbestos exposure, and review previously published cases of SMPM (Table I).

\section{Case report}

A 41-year-old male patient presented to the Department of Cardiothoracic Surgery of the Affiliated Hospital of North Sichuan Medical College (Nanchong, China) in May, 2016 with a chief complaint of left-sided chest pain for 1 month. The patient's height was $\sim 178 \mathrm{~cm}$ and he weighed $70 \mathrm{~kg}$, he was a non-smoker and had no past history of exposure to carcinogenic chemicals, such as asbestos. The past medical history was unremarkable and there was no family history of cancer. There was no history of cough, fever, or hemoptysis, and the vitals on admission were normal. Physical examination revealed no lymphadenopathy. The findings on lung function tests were within the normal range [forced expiratory volume in $1 \mathrm{sec}$ (FEV1) 4.41 1, forced vital capacity (FVC) 5.281 , and a FEV1/FVC ratio of 0.83 ]. A chest computed tomography (CT) scan revealed locally thickened left visceral and parietal pleura, associated with intermingled pulmonary infiltrative shadowing. The tumor had smooth margins with a wide tumor base. A cranial CT scan revealed no abnormal masses in the brain (Fig. 1B). A bone scan using positron emission CT detected no invasion or distant metastasis. On three-dimensional CT imaging, the ribs were not invaded. Doppler ultrasound of the abdomen and cervical area revealed no lymph node or distant metastatic lesions in other organs. The findings on CT-guided percutaneous biopsy of the mass were not significant.

The patient underwent surgery on April 10, 2016. A 20-cm incision was made at the left 6 th intercostal space and a mass originating from the pleura was identified. Extrapleural pneumonectomy (EPP) was performed as the tumor invaded 
Table I. Previously published cases of sarcomatoid malignant pleural mesothelioma.

\begin{tabular}{lccccccc}
\hline Authors & $\begin{array}{c}\text { Year } \\
\text { of publication }\end{array}$ & MPM & SMPM & Sex & $\begin{array}{c}\text { Age, } \\
\text { years }\end{array}$ & $\begin{array}{c}\text { Intracranial } \\
\text { metastasis }\end{array}$ & $\begin{array}{c}\text { Survival } \\
\text { time, months }\end{array}$ \\
(Refs.)
\end{tabular}

MPM, malignant pleural mesothelioma; SMPM, sarcomatoid MPM; M, male; F, female.
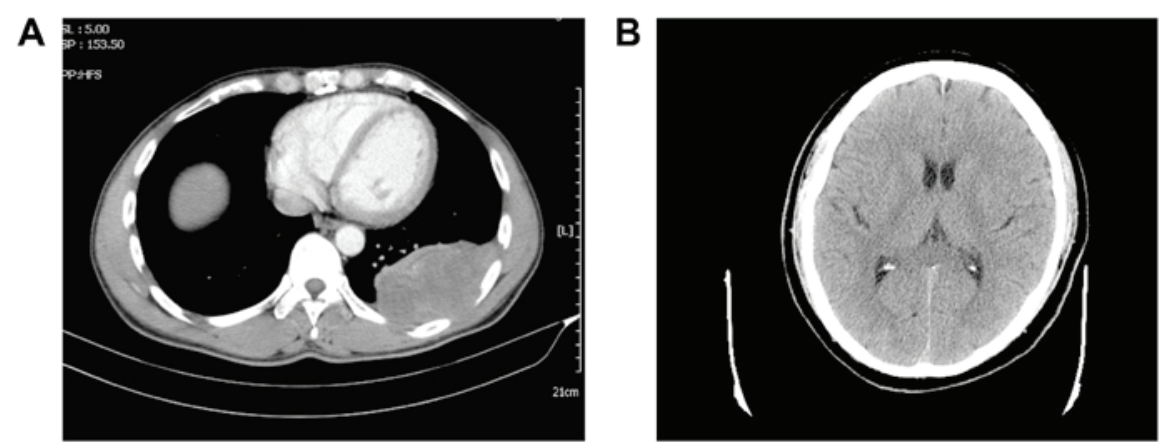

Figure 1. (A) Contrast-enhanced computed tomography (CT) scan revealed a solitary sharp homogeneous enhancing mass on the left chest wall, abutting the pleura, sized 12x10x8 cm. Pleural effusion was not observed. (B) The preoperative cranial CT scan revealed no masses in the brain.

the left inferior lobe. The solid tumor was sized $\sim 12 \times 10 \times 8 \mathrm{~cm}$ and it was yellowish-white on cross-section. To confirm the ribs were not invaded, part of the left 5th and 6th ribs was removed for intraoperative frozen section biopsy, and the results was negative for invasion. The duration of entire procedure was $\sim 2 \mathrm{~h}$. The intraoperative blood loss was $\sim 500 \mathrm{ml}$ and the patient received a transfusion of 2 units of whole blood.

Pathological examination of the pleural mass was performed. The examination of hematoxylin and eosin-stained sections revealed papillary formations or sheets of spindle cells. Cellular atypia and nuclear fission were observed on high magnification. Bubble-like cells were also identified focally. On immunohistochemical examination, the tumor was pan-cytokeratin $(\mathrm{CK})^{+}$, $\mathrm{CK}^{+}, \mathrm{CK}^{2} 8^{+}$, epithelial membrane antigen ${ }^{-}$, calretinin ${ }^{-}, \mathrm{CK} 5 / 6^{-}$, P63-, there was no obvious loss of INI-1 expression, CD34', Wilms tumor-1', CD31', ERG-, leukocyte common antigen', $\mathrm{Ki}-67^{+}(30 \%)$ and $\mathrm{S}-100^{+}$(partially). These characteristics were consistent with the diagnosis of SMPM (Fig. 2).

Postoperative adjuvant chemotherapy was not performed due to financial difficulties. Five months after the surgery, the patient visited our hospital with new complaints of paralysis of the left leg and chest pain. A follow-up chest contrast-enhanced $\mathrm{CT}$ revealed recurrence at the site of the excision. A cranial $\mathrm{CT}$ scan was also performed and revealed 4 intracranial metastatic lesions: A $0.5-\mathrm{cm}$ mass located in the posterior horn of the lateral ventricle of the left temporal lobe, and three more lesions in the frontal lobe, parietal lobe and basal ganglia region of the right cerebrum, sized $\sim 1,2$ and $2 \mathrm{~cm}$, respectively. There was edema surrounding the mass lesions (Fig. 3A-C). The patient was discharged without any treatment and succumbed to the disease 1 week later.

The present case report was approved by the Ethics Committee of the Affiliated Hospital of North Sichuan Medical College, and written informed consent was obtained from the patient for publication of this case report and the accompanying images.

\section{Discussion}

Approximately $80 \%$ of patients with MPM have a history of asbestos exposure (12). The period between asbestos exposure and the onset of MPM is reported to be $\sim 30-40$ years (13). MPM originates from the mesothelium of the parietal pleura and is associated with a poor prognosis $(2,12)$, with a median survival period of 11.5-15.3 months. However, SMPM carries a significantly worse prognosis, with a median survival of 4.2-5.0 months $(14,15)$. Only early-stage EPP may prolong the survival of patients with MPM (16); however, as MPM is either asymptomatic or associated with a non-specific presentation, early diagnosis is usually difficult $(2,12)$.

Distant metastases of MPM by hematogenous spread are estimated to occur in $>10 \%$ of the cases at later stages of the 

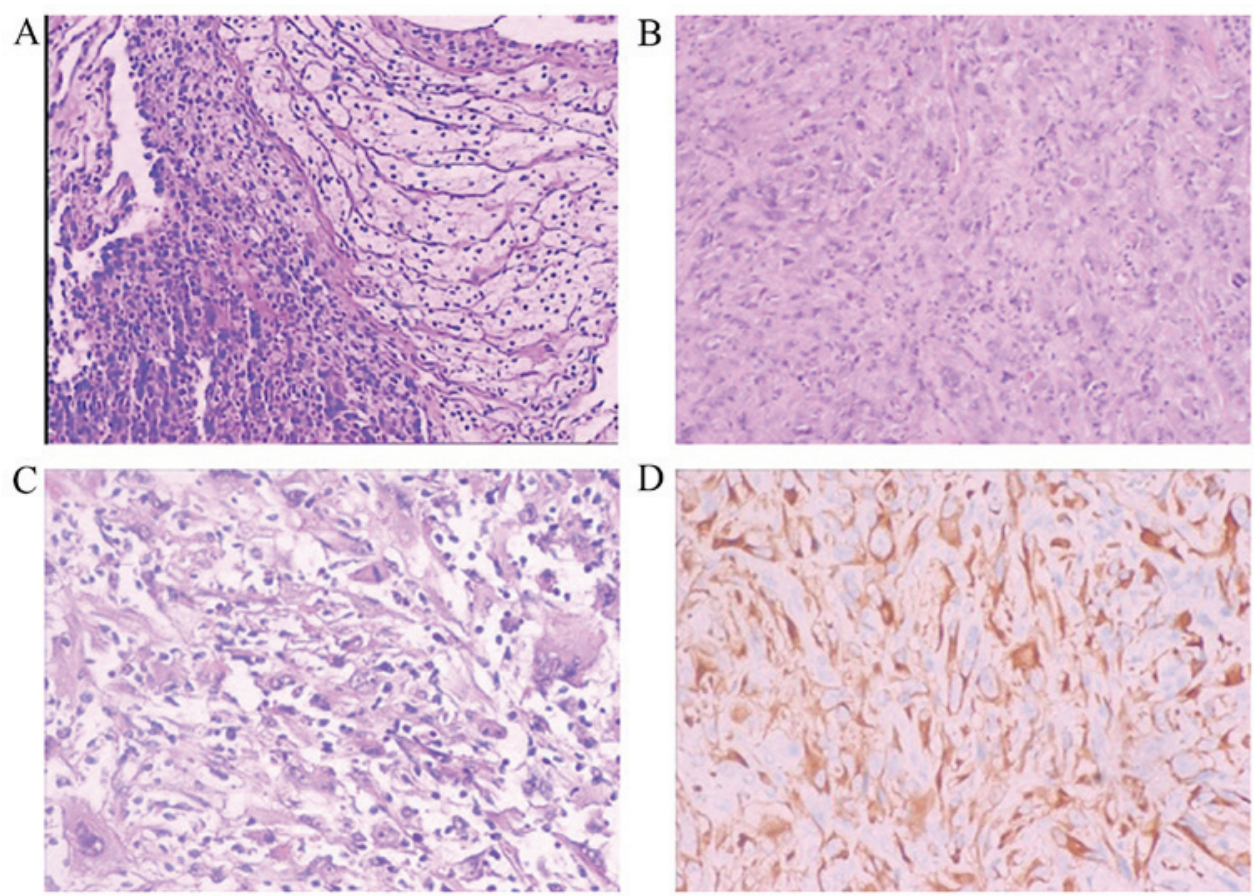

Figure 2. Pathology results of the pleural mass. Papillary formations or sheets of spindle cells were observed, with cellular atypia, nuclear fission and focal bubble-like cells observed on high magnification. Hematoxylin and eosin staining, magnification (A) x50, (B) x100 and (C) x200. (D) Immunohistochemical examination revealed that the tumor cells were positive for PCK, CK7, CK18; magnification, x100. The tumor cells were negative for epithelial membrane antigen, calretinin, CK5/6, P63, CD34, Wilms tumor-1, CD31, ERG and leukocyte common antigen.

A

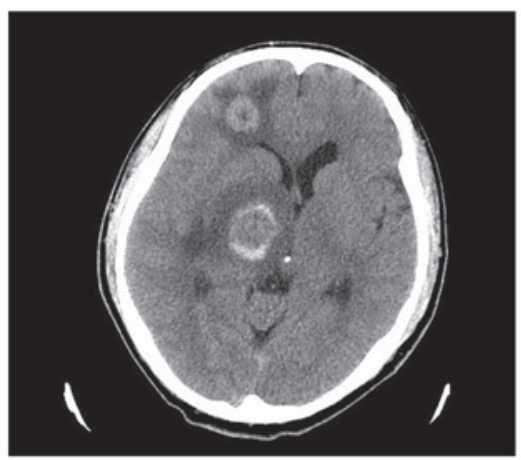

B

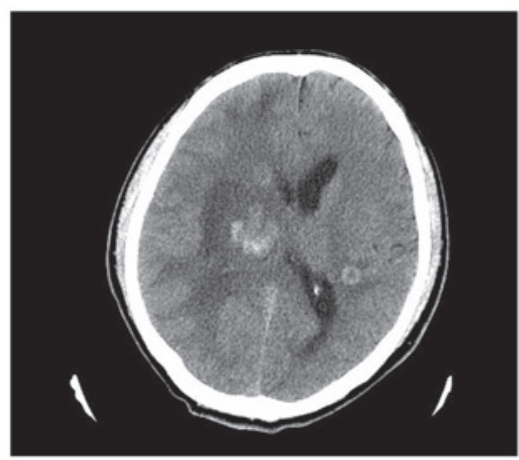

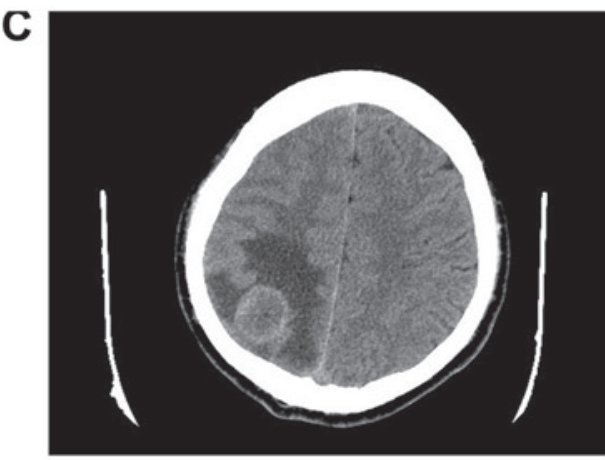

Figure 3. On postoperative computed tomography examination, masses were identified (A) in the right frontal lobe ( 1 $\mathrm{cm})$, (B) in the right parietal lobe $(\sim 2 \mathrm{~cm})$ and $(\mathrm{C})$ in the basal ganglia region of the right hemisphere $(\sim 2 \mathrm{~cm})$. Edema was observed in the brain tissue surrounding the masses.

disease (17). The most frequently involved organs are the liver, adrenal gland, kidney and contralateral lung (18-22). There have only been few reports on intracranial metastasis of MPM (7-11). Hurmuz et al reported a case of multiple intracranial metastases from MPM, but not SMPM (9). Falconieri et al summarized 93 cases of MPM with distant metastases, among which only 3 intracranial metastases were observed. All 3 cases were SMPMs, and only 1 case without CNS symptoms involved multiple intracranial metastases (8).

The incidence of the three subtypes of MPM is as follows: Epithelioid subtype, $60 \%$; sarcomatoid subtype, $10 \%$; the biphasic subtype, exhibiting a mixed histological pattern, accounts for the remainder of the cases (23). The epithelioid subtype has the best prognosis, whereas the sarcomatoid has the worst (23). Wagner et al reported that, among 200 cases of MPM, there were only 25 SPM cases and they all exhibited short survival (24).
Pathological confirmation of SMPM is difficult preoperatively (25). With immunohistochemistry, calretinin is the most commonly used marker for MPM, which is often positive in epithelioid MPM, but negative in SMPM (26-28). In the present case, calretinin was negative, consistently with previous reports.

There was recurrence in the thorax and multiple intracranial metastatic tumors $\sim 5$ months after EPP. There is currently no widely accepted curative approach to intracranial metastases of MPM. Surgery or stereotactic radiosurgery would be considered as treatments for solitary intracranial metastasis from MPM (11); however, there has been no documented treatment for multiple intracranial metastases from MPM. Whole-brain irradiation or/and chemotherapy would be considered as reasonable treatment options.

The most common symptoms of SMPM include coughing, hemoptysis, weight loss, chest pain, dyspnea, fatigue, and fever due to recurring pneumonia (3). In the present case, 
the patient presented with only chest pain. Smoking may also be a risk factor, but our patient was not a smoker. The CT findings suggested MPM, which usually affects the lungs. The recommended treatment included surgery, radiation and chemotherapy; however, only surgery was performed due to financial constraints. Supportive treatment may relieve some of the symptoms. Prognosis in MPM may be difficult to assess consistently, due to the great variability in the time before diagnosis and the rate of disease progression. Our patient only survived for $\sim 5$ months after surgery, as the disease exhibited an aggressive clinical course.

EPP appears to be the only radical treatment option for locally advanced MPM, and may be able to eradicate macroscopic disease in selected patients. However, the long-term survival remains unsatisfactory due to the high incidence of recurrence, particularly locoregional treatment failure, and more effective treatments are urgently required (16).

Cytological assessment of pleural effusion may not be sufficiently sensitive and specific (29). In addition, fine-needle biopsy is not primarily recommended, as it is associated with low sensitivity $(\sim 30 \%)$. In the present case, CT-guided percutaneous needle biopsy was performed, but the findings were not significant. Deng et al suggested that SMPM may only be confirmed by full-thickness biopsy (30).

In conclusion, SMPM has not been extensively investigated due to the scarcity of reported cases. We herein present a case of multiple intracranial metastases from a giant SMPM, emphasizing the rare metastatic pattern, aggressive clinical course and poor response to treatment, along with a review of the previously published relevant literature.

\section{Acknowledgements}

The authors would like to thank Dr Xiaoguang Guo of the Department of Pathology, Nanchong Central Hospital, The Second Clinical Institute of North Sichuan Medical College (Nanchong, China) for the support and assistance.

\section{References}

1. Crotty TB, Myers JL, Katzenstein AL, Tazelaar HD, Swensen SJ and Churg A: Localized malignant mesothelioma. A clinicopathologic and flow cytometric study. Am J Surg Pathol 18: 357-363, 1994.

2. Makimoto G, Fujiwara K, Fujimoto N, Yamadori I, Sato T and Kishimoto T: Phrenic nerve paralysis as the initial presentation in pleural sarcomatoid mesothelioma. Case Rep Oncol 7: 389-392, 2014.

3. Nakano T, Hamanaka R, Oiwa K, Nakazato K, Masuda R and Iwazaki M: Localized malignant pleural mesothelioma. Gen Thorac Cardiovasc Surg 60: 468-474, 2012.

4. Stahel RA, Weder W and Felip E; ESMO Guidelines Working Group: Malignant pleural mesothelioma: ESMO clinical recommendations for diagnosis, treatment and follow-up. Ann Oncol 19 (Suppl 2): ii43-ii44, 2008.

5. Tanzi S, Tiseo M, Internullo E, Cacciani G, Capra R, Carbognani P, Rusca M, Rindi G and Ardizzoni A: Localized malignant pleural mesothelioma: Report of two cases. J Thorac Oncol 4: 1038-1040, 2009.

6. Yang H, Testa JR and Carbone M: Mesothelioma epidemiology, carcinogenesis, and pathogenesis. Curr Treat Options Oncol 9: 147-157, 2008

7. Davies MJ, Ahmedzai S, Arsiwala SS and Leverment JN Intracranial metastases from malignant pleural mesothelioma. Scand J Thorac Cardiovasc Surg 29: 97-99, 1995.
8. Falconieri G, Grandi G, DiBonito L, Bonifacio-Gori D and Giarelli L: Intracranial metastases from malignant pleural mesothelioma. Report of three autopsy cases and review of the literature. Arch Pathol Lab Med 115: 591-595, 1991.

9. Hurmuz P, Zorlu F, Cansiz C and Emri S: Malignant pleural mesothelioma with brain metastasis. J BUON 14: 123-125, 2009.

10. Mah E, Bittar RG and Davis GA: Cerebral metastases in malignant mesothelioma: Case report and literature review. J Clin Neurosci 11: 917-918, 2004.

11. Winfree CJ, Mack WJ and Sisti MB: Solitary cerebellar metastasis of malignant pleural mesothelioma: Case report. Surg Neurol 61: 174-179, 2004.

12. Galetta D, Catino A, Misino A, Logroscino A and Fico M Sarcomatoid mesothelioma: Future advances in diagnosis, biomolecular assessment, and therapeutic options in a poor-outcome disease. Tumori 102: 127-130, 2016.

13. Carbone M, Kratzke RA and Testa JR: The pathogenesis of mesothelioma. Semin Oncol 29: 2-17, 2002.

14. Balduyck B, Trousse D, Nakas A, Martin-Ucar AE, Edwards J and Waller DA: Therapeutic surgery for nonepithelioid malignant pleural mesothelioma: Is it really worthwhile? Ann Thorac Surg 89: 907-911, 2010.

15. Marshall AD, Bayes HK, Bardgett J, Wedderburn S, Kerr KM and Currie GP: Survival from malignant mesothelioma: Where are we now? J R Coll Physicians Edinb 45: 123-126, 2015.

16. Nakas A, von Meyenfeldt E, Lau K, Muller S and Waller D: Long-term survival after lung-sparing total pleurectomy for locally advanced (International Mesothelioma Interest Group Stage T3-T4) non-sarcomatoid malignant pleural mesothelioma. Eur J Cardiothorac Surg 41: 1031-1036, 2012

17. Sussman J and Rosai J: Lymph node metastasis as the initial manifestation of malignant mesothelioma. Report of six cases. Am J Surg Pathol 14: 819-828, 1990

18. Brenner J, Sordillo PP, Magill GB and Golbey RB: Malignant mesothelioma of the pleura: Review of 123 patients. Cancer 49: 2431-2435, 1982.

19. Cheng WF and Berkman AW: Malignant mesothelioma with bone metastases. Med Pediatr Oncol 18: 165-168, 1990.

20. Law MR, Hodson ME and Heard BE: Malignant mesothelioma of the pleura: Relation between histological type and clinical behaviour. Thorax 37: 810-815, 1982.

21. Lester $\mathrm{T}$ and $\mathrm{Xu} \mathrm{H}$ : Malignant pleural mesothelioma with osseous metastases and pathologic fracture of femoral neck. Appl Immunohistochem Mol Morphol 16: 507-509, 2008.

22. Machin T, Mashiyama ET, Henderson JA and McCaughey WT: Bony metastases in desmoplastic pleural mesothelioma. Thorax 43: 155-156, 1988.

23. Pass HI, Vogelzang N, Hahn S and Carbone M: Malignant pleural mesothelioma. Curr Probl Cancer 28: 93-174, 2004.

24. Wagner JC, Sleggs CA and Marchand P: Diffuse pleural mesothelioma and asbestos exposure in the North Western Cape Province. Br J Ind Med 17: 260-271, 1960.

25. Suter M, Gebhard S, Boumghar M, Peloponisios N and Genton CY: Localized fibrous tumours of the pleura: 15 new cases and review of the literature. Eur J Cardiothorac Surg 14: 453-459, 1998.

26. Hillerdal G and Elmberger G: Malignant mediastinal tumor with bone formation-mesothelioma or sarcoma? J Thorac Oncol 2: 983-984, 2007.

27. Kim KC and Vo HP: Localized malignant pleural sarcomatoid mesothelioma misdiagnosed as benign localized fibrous tumor. J Thorac Dis 8: E379-E384, 2016.

28. Kushitani K, Takeshima Y, Amatya VJ, Furonaka O, Sakatani A and Inai K: Differential diagnosis of sarcomatoid mesothelioma from true sarcoma and sarcomatoid carcinoma using immunohistochemistry. Pathol Int 58: 75-83, 2008.

29. Scherpereel A, Astoul P, Baas P, Berghmans T, Clayson H, de Vuyst P, Dienemann H, Galateau-Salle F, Hennequin C, Hillerdal G, et al: Guidelines of the European respiratory society and the European society of thoracic surgeons for the management of malignant pleural mesothelioma. Eur Respir J 35: 479-495, 2010 .

30. Deng CS, Sasada S, Izumo T, Nakamura Y, Tsuta K and Tsuchida T: Sarcomatoid malignant pleural mesothelioma confirmed by full-thickness biopsy. Chin Med J (Engl) 126: 3391-3392, 2013

This work is licensed under a Creative Commons Attribution-NonCommercial-NoDerivatives 4.0 International (CC BY-NC-ND 4.0) License. 